\title{
III. „Nationale Verhältnisse“ und Staatssicherheit: Das Arbeitsmarktschutzgesetz von 1928 und die Übereinkunft mit Deutschland (1924-1929)
}

Neu war im Jahr 1924, daß der Ruf nach einer Entfernung der Reichsdeutschen aus der tschechoslowakischen Industrie zunehmend stärker im Zusammenhang mit der Polemik gegen die deutsche Kapitalmacht erschallte. Anfang Februar trat der „Venkov“, das Organ der Agrarpartei, mit einem Nationalisierungsprogramm in die Öffentlichkeit, zu dem als Kernpunkt die Entfernung reichsdeutscher Kräfte aus leitenden Positionen gehörte. Im Visier hatte das Blatt verteidigungswichtige Unternehmen wie die Aussiger Chemie und die Kohlengruben im grenznahen nordböhmischen bzw. mährischschlesischen Revier. Nach dem Umsturz sei die Wirtschaft in deutschen Händen verblieben; weil die Tschechen auf angestammtem Boden weiterhin Sklaven seien, müßten die Hebel der politischen Macht zur Überführung dieser Industrien in verläßliche Hände eingesetzt werden, denn nur so sei im Kriegsfall, nach Abgang der deutschen Kader, die Stillegung dieser Werke zu verhindern. Evolutionäre Methoden gegen die Reichsdeutschen an den Schalthebeln der Macht genügten nicht. ${ }^{1}$

Das Manifest wirkte als Fanal; die Prager Gesandtschaft übermittelte es dem Auswärtigen Amt. ${ }^{2}$ Koch verortete den aggressiven Ausfall als Spätfolge der inflationsbedingten Flucht deutscher Anleger aus der Reichsmark in tschechoslowakische Wertpapiere; den „Ausverkauf“ hatten die nationaldemokratischen „Národní listy“ im August 1923 als Beginn der „Tributpflichtigkeit“ der Tschechoslowakei gegenüber dem ausländischen Kapital etikettiert. Als Hintergrund darf das tschechische Überfremdungstrauma vermutet werden. ${ }^{3}$ Der Zeitpunkt der Kampagne war aber auch aus anderen Gründen nicht zufällig: Das politische Chaos in den Anrainerländern Bayern, Sachsen und Thüringen und die Furcht vor einer Restauration der Hohenzollern im Reich hatten die Gefahr militärischer Verwicklungen mit Deutschland in greifbare Nähe gerückt. Am 24. Januar 1924 unterzeichneten Prag und Paris einen Bündnis- und Freundschaftsvertrag, der nicht veröffentlichte - militärischen Passagen enthielt ${ }^{4}$; am 5. Mai wurde beim Generalstab ein Interministerielles Arbeitsgremium für Staatsverteidigungsangelegenheiten eingerichtet. $^{5}$ Anfang Juni lag eine Ausarbeitung des Verteidigungsministeriums über die nationalen Verhältnisse in der kriegswichtigen Industrie vor, die sich auf Berichte von Behörden und nationaltschechischen Presseorganen wie der Wochenschrift „Samostatnost“ und der im rechten politischen Spektrum angesiedelten „28. říjen“ über die Lage in der Chemie und bei Kohle und Eisen stützte; aber auch eine Meldung der kommu-

1 Venkov vom 7.2.1924.

2 PA, R 73 823, Deutsche Paßstelle Reichenberg an AA, 12. 2. 1924. - BArch-B, RMWi, 2890, Gesandtschaft Prag an AA, 14.2 1924.

3 Vgl. hierzu den Bericht des Prager Wirtschaftsattachés Köster in BArch-B, RMWi, 20 258, Gesandtschaft Prag an AA, 7.8.1923.

4 Campbell, Confrontation, S. $125 \mathrm{ff}$.

5 Vgl. dazu im Detail unten S. 355 f. 
nistischen „Rudé právo“ verschmähte das Ministerium nicht als Quelle. ${ }^{6}$ In diesem Papier, welches das vom „Venkov" angeschlagene Motiv entfaltete, äußerten sich die Militärs beunruhigt über die Zustände in den großen Kohlengesellschaften im Brüxer und im Falkenau-Elnbogener Gebiet, welche zusammen 165 deutsche, aber nur 15 tschechische Bergingenieure beschäftigten. Die Tschechische Chemische Gesellschaft für Wissenschaft und Industrie berichtete über ähnliche Verhältnisse in ihrer Branche. Ein anderer neuralgischer Punkt war die Poldihütte in Kladno: Dort waren nach Auskunft des Polizeikommissariates zehn von 25 Ingenieuren Ausländer. Von den restlichen 15, tschechoslowakischen Staatsbürgern, waren 13 deutscher Nationalität und nur zwei Tschechen. 16 der (Reichs- oder einheimischen) Deutschen stufte das Kommissariat als "fanatische Deutsche" ein, nur acht als nationalpolitisch indifferent. Außerdem waren 77 von 90 Angehörigen der Unternehmensverwaltung Deutsche. In den Witkowitzer Berg- und Hüttenwerken stellten Reichsdeutsche und Österreicher sieben, tschechoslowakische Staatsbürger deutscher Nationalität 84 und die Nationaltschechen nur 9 Prozent der Beamten, Aufseher und Werkmeister. Sechs von sieben Prokuristen, 42 von 44 Abteilungsleitern, 11 von 12 Werksärzten waren Deutsche. Revisionsabteilung und Buchhaltung waren fest in deutscher Hand. Ähnlich lagen die Dinge bei der Prager Eisengesellschaft und in einer Reihe anderer Unternebmen.

Legte das Verteidigungsministerium auch großen Wert auf den "staatsaufbauenden“ Charakter der Angestellten und war man sich dort auch der Tatsache bewußt, daß für eine sofortige Übernahme der Schaltstellen der Wirtschaft die personellen Ressourcen schlicht nicht verfügbar waren, so hielt man doch im Interesse einer längerfristigen Umschichtung der nationalen Verhältnisse in der verteidigungswichtigen Industrie Erhebungen für unabdingbar. Geprüft werden müsse, ob man den unentbehrlichen Fachleuten Einheimische zur Einarbeitung an die Seite stellen könne, wie die Einhaltung solcher Auflage zu kontrollieren sei und ob man nicht Aufenthaltserlaubnisse unter Einschaltung des Verteidigungsministeriums nur auf Widerruf und nach Einzelfallprüfung ausstellen solle. Unmittelbar geboten sei die Entfernung unzuverlässiger Ausländer in staatlichen Betrieben, bei Eisenbahn und Post. Privatunternehmen, die im Zuge der Nostrifizierung, hinsichtlich der Genehmigung neuer Betriebe, hinsichtlich Kapitalerhöhungen oder Statutenänderungen, Staatsaufträgen, in Steuer- oder Tariffragen auf die Behörden angewiesen waren, sollte eine Erhöhung der Inländerbeschäftigung zur Auflage gemacht werden. Leitende Positionen waren mit nationaltschechischen Beamten proportional zum Anteil der Tschechen an der Belegschaft zu besetzen. Die innere Verwaltung sollte dem Militär Listen der ausländischen Angestellten und der in verteidigungswichtigen Betrieben beschäftigten unzuverlässigen tschechoslowakischen Staatsbürger zur Verfügung stellen.?

Die Rechtslage änderte sich vorerst trotzdem nicht wesentlich, abgesehen von Regierungsverordnung Nr. 163 vom 18. Juni 1925, die für die Erteilung der Arbeitsbewilligung eine Gebühr mit der beträchtlichen Spannweite zwischen 20 und 1000 Kronen festsetzte: über die konkrete Höhe entschied das Ministerium für soziale Fürsorge in freiem Ermessen. ${ }^{8}$ Begründet wurde dies mit ähnlichen Maßnahmen der Nachbarstaa-

6 28. ř́jen vom 24.2. 1924. - Samostatnost Nr. 11 und Rudé právo vom 10.4. 1924.

7 SÚA, MSP, Karton 1568, Mappe 2, MNO an MSP, 8. 6. 1924.

8 Heindl, Aufenthalt. 
ten. ${ }^{9}$ Für einen Reichsdeutschen wurden in der Regel 300 bis 500 Kronen gefordert. Die Genehmigung galt für maximal ein halbes Jahr, dann war der prohibitive Satz erneut fällig. Die deutsche Gesandtschaft forderte deshalb eine Anpassung an die deutlich niedrigeren deutschen Gebühren von 3 bis 5 RM. ${ }^{10}$ Ende Februar 1926 wurde verfügt, daß nach dem 30. April 1923 zugereiste Ausländer, die ohne Bewilligung eine Stelle angetreten hatten, aufzufordern seien, ihr Arbeitsverhältnis zu lösen oder sich binnen vier Wochen eine nachträgliche Genehmigung zu verschaffen. ${ }^{11}$

Motor für die Änderung der „nationalen Verhältnisse“ war Ende der zwanziger Jahre in erster Linie der Tschechoslowakische Nationalrat. Von seinen Fachkommissionen war vor allem die für volkswirtschaftliche Fragen von Bedeutung. ${ }^{12}$ Geleitet wurde sie von Josef Drachovský; zu ihren Mitgliedern zählten der langjährige Mitarbeiter und - ab 1932 - Generalsekretär der Prager Handels- und Gewerbekammer, Zdeněk Fafl, sowie der spätere nationaldemokratische Handelsminister Josef Matoušek. Am 22. Juni 1927 erörterte die Kommission den Plan einer „Evidenz“ der „nationalen Verhältnisse " in der Wirtschaft; in dieser Angelegenheit waren bereits regelmäßige Konsultationen mit General Bartoš, dem Vertrauensmann der Kommission im Generalstab, vereinbart. Die Einschaltung des Nationalrats in vertrauliche Planspiele des Militärs, im Kriegsfall deutsche Direktoren und Ingenieure zu ersetzen, war das wohl deutlichste Indiz für die Einbindung in die inneren Zirkel der Macht. ${ }^{13}$ Fluchtpunkt der am 9. November 1927 verabschiedeten Arbeitsrichtlinien der volkswirtschaftlichen Kommission war die Absicherung der politischen Unabhängigkeit der Republik durch die wirtschaftliche. ${ }^{14}$ Im Winter 1927/28 schloß die Kommission zu diesem Zweck eine formelle Kooperationsvereinbarung mit Bartoš. Bis zum Herbst $1928^{15}$ erörterte sie wichtige Einzelprobleme wie die wünschenswerte Bevorzugung nationaltschechischer Unternehmer bei der Vergabe von Konzessionen und Krediten ${ }^{16}$, allfällige Interventionen bei Unternehmensveräußerungen sowie Pläne und Projekte zur Gründung nationaltschechischer Betriebe. ${ }^{17}$ Über die tschechischen Mitglieder von Verwaltungsräten

9 Egerer Zeitung vom 24.2.1927.

10 PA, R 74 032, Gesandtschaft Prag, Verbalnote vom 3. 5. 1926.

11 DHI, Tätigkeitsbericht 1926, S. 101.

12 SÚA, NRC, N, Karton 413/2/236-7, Übersicht über die Volkswirtschaftliche Organisation des Nationalrats vom 24. 5. 1927.

13 SÚA, NRČ, N, Karton 414, Bericht über die Tätigkeit der Volkswirtschaftlichen Kommission für die Sitzung am 29.11.1928.

14 SÚA, NRČ, N, Karton 413/2/236-7, Tschechoslowakischer Nationalrat, Einladung zur Sitzung vom 5.11.1927.

15 Das Gremium tagte in vergleichsweise großen, oft mehrmonatigen Abständen: Zwischen dem Herbst 1927 und dem Herbst 1928 fanden Sitzungen statt am 9. November 1927, am 12. Januar 1928, am 17. Februar, 28. Juni, 18. Oktober und 29. November 1928: Vgl. die Sitzungsprotokolle in SÚA, NRČ, N, Karton 413/2/236-7 und 414.

16 Hierzu ein Beispiel aus den dreißiger Jahren: Der Nationalrat sprach sich beim Handelsministerium - mit Erfolg - gegen die Vergabe einer Konzession zur Produktion von Radiolampen an die Firma OSRAM-Glühlampen aus. Dieses Unternehmen arbeitete mit reichsdeutschem Kapital und hatte einen überwiegend deutschen Verwaltungsrat: Vgl. SÚA, NRČ, P, Karton 145/1, Bericht für die Sitzung der Volkswirtschaftlichen Kommission am 10.5.1933.

17 Der Nationalrat machte etwa 1927 den Zentralverband darauf aufmerksam, daß bei Sumperk eine Gießerei zum Verkauf stand, um die sich vertraulichen Informationen zufolge Schicht bewerbe: Vgl. SÚA, NL Hodáč, Karton 38, A/I-D, Zentralverband an Verband der tschechoslowakischen eisenschaffenden Industrie, 24. 3. 1927. 
und über den Hebel der Staatsaufträge nahm der Nationalrat Einfluß auf die „nationalen Verhältnisse“, er machte sich anläßlich der Besetzung leitender Posten bemerkbar, gab diesbezüglich Empfehlungen $a^{18}$ und suchte leitende Persönlichkeiten der Wirtschaft auf seine Ziele einzuschwören. ${ }^{19}$ Bevorzugtes Instrument waren Einzelinterventionen bei den Behörden. Ein weiteres wichtiges Interessengebiet war das Wirtschaftsverbandswesen: Im Vorfeld des Zusammenschlusses von Zentralverband und Hauptverband suchte der Nationalrat bei Generalsekretär Hodáč auf die Modalitäten der Repräsentation von Tschechen und Deutschen in der Dachorganisation Einfluß zu nehmen. 1928 erstattete er dem Ministerrat, dem Koalitionsausschuß der Regierungsparteien und der Präsidentenkanzlei Bericht über die nationalen Verhältnisse in den Gruben und Hütten, in der zentralen Kohlenverkaufsstelle und im Kohlenhandel. Mit einigen Ministerien hatte man stabile Beziehungen etabliert; den Kontakt zum Handelsministerium vermittelten der frühere Handelsminister Peroutka und Sektionschef Benda. ${ }^{20}$ Bereitwillige Unterstützung genoß der Nationalrat beim Präsidium des Ministerrats, besonderes Verständnis für seine Ziele konnte dem Verteidigungsministerium bescheinigt werden. ${ }^{21}$

In der Arbeitsmarkpolitik und in der Frage der "nationalen Verhältnisse“ wurden um die Mitte der zwanziger Jahre in der Öffentlichkeit der Republik Stimmen laut, die die Ersetzung der aktuellen, lediglich auf dem Erlaß vom 17. Dezember 1920 basierenden Regelung durch eine solide gesetzliche Grundlage forderten. Die politischen Rahmenbedingungen leisteten diesen Bestrebungen Vorschub: Im dritten, seit dem 26. Oktober 1926 amtierenden, Kabinett Švehla verfügte die Agrarpartei, die sich der Frage der „nationalen Verhältnisse“ bereits angelegentlich gewidmet hatte, über eine außerordentlich starke Position. Außer dem Ministerpräsidenten war Verteidigungsminister Udržal Mitglied der Partei; das von dem parteilosen Černý geleitete Innenministerium stand unter dem direkten Einfluß Švehlas. Zudem begannen nun einflußreiche Banken- und Industriekreise, an erster Stelle Švehlas Jugendfreund Jaroslav Preiss, sich von den im Niedergang begriffenen Nationaldemokraten zur Agrarpartei umzuorientieren, was einen Ausgleich der industriellen und landwirtschaftlichen Interessen begünstigte.

Mittelbar spielte auch der Eintritt der deutschen Aktivisten in die Regierung eine Rolle. An sich bedeutete dieser einen Ruck zur Mitte und eine Abkehr von den Radikalen beider nationaler Lager, den Deutschnationalen und den Nationaldemokraten. Nun waren die deutschen Minister ohne jegliche Vorabkonzessionen in nationalpolitischen

18 Der Direktor eines Eisenwerks im Bezirk Troppau war bereit, einen tschechischen Fachmann als leitenden Techniker einzustellen, und verlangte von der dortigen Filiale des Nationalrats eine Empfehlung: Vgl. SÚA, NRČ, N, Karton 414/1/237, Bericht für die Sitzung des Vorstands der Volkswirtschaftlichen Kommission am 1.10.1936.

19 Auch hierzu ein Beispiel aus den dreißiger Jahren: Anläßlich eines Antrittsbesuchs des Nationalrats bei dem neuen Direktor der Königinhofer Zementfabrik wurde dieser auf seine Pflichten bzgl. der nationalen Verhältnisse im Betrieb hingewiesen: Vgl. SÚA, NRČ, P, Karton 145/1, Bericht für die Sitzung der Volkswirtschaftlichen Kommission am 10. 5.1933.

20 SÚA, NRČ, N, Karton 414, Bericht für die Sitzung der Volkswirtschaftlichen Kommission am 17.2. 1928. - Bericht der Volkswirtschaftlichen Kommission für die Versammlung des Exekutivausschusses am 26. 4. 1928. - SÚA, NRČ, N, Karton 413/2/236-7, Sitzung der Volkswirtschaftlichen Kommission am 18. 10. 1928. - SÚA, NRČ, N, Karton 414, Bericht über die Tätigkeit der Volkswirtschaftlichen Kommission für die Sitzung am 29.11.1928.

21 Der Nationalrat wandte sich an die Agrarbank und an Preiss, beide Male allerdings ohne Erfolg. 
Fragen wie der Bodenreform, der Staatsbeamten- und der Schulfrage ins Kabinett eingetreten, so daß ihnen, wie der österreichische Gesandte Marek als kundiger Beobachter formulierte, „nur fromme Wünsche“ blieben, deren Erfüllung Švehla abblocke.22 Der deutsche Gesandte Koch konstatierte kleinlichen Parteigeist und persönlichen Ehrgeiz der aktivistischen Politiker, unter denen er Führer von Format nicht auszumachen vermochte. Die Schuld an der Einflußlosigkeit der Deutschen im Land schrieb er deshalb zu einem guten Teil ihnen selbst zu: „Gewiss, es geht ihnen schlecht; aber das Klagen darüber ist zum guten Teil ein Kokettieren mit der eigenen Schlappheit. “ Man jammere nach Hilfe aus dem Reich, ignoriere aber die eigene zahlenmäßige Stärke, wirtschaftliche und kulturelle Potenz, angesichts derer die Deutschen „keine schutzbedürftige Minderheit, sondern ein wesentlicher Bestandteil des Ganzen“ seien, dem man sein Recht nicht auf Dauer vorenthalten könne. ${ }^{23}$ Läßt sich der Regierungseintritt der Aktivisten bei Licht besehen auch schwerlich als grundstürzende Änderung der nationalitätenpolitischen Kräfteverhältnisse interpretieren, so nahmen ihn tschechische Nationalisten doch zum Anlaß für Warnungen vor einer „Germanisierungswelle“. Das volkssozialistische „České slovo“24 konstatierte Anfang Dezember 1926 eine „zunehmende Dreistigkeit“ der Deutschen, welche sich etwa in der Gründung eines „Hilfsvereins reichsdeutscher Staatsangehöriger in Nordmähren und in Schlesien“ manifestiere. In der Leitung dieser Organisation, „České slovo“ zufolge ein Sammelbecken der Irredenta, saßen nicht zuletzt auch prominente Repräsentanten der deutschen Wirtschaft.

Das von „České slovo“ in diesem Zusammenhang geforderte Gesetz zum Schutz des einheimischen Arbeitsmarkts vertrug sich allerdings schlecht mit dem internationalen Entwicklungstrend: Die 1927 auf der Genfer Weltwirtschaftskonferenz erörterte generelle Gleichstellung von In- und Ausländern hinsichtlich Aufenthalt und Beschäftigung fügte sich in das umfassendere Projekt einer Rekonstruktion der internationalen Wirtschaftsbeziehungen im Geist des Freihandels. Auch die Stockholmer Verhandlungen der Internationalen Handelskammer bezweckten die Wiederherstellung der Freizügigkeit auf den Arbeitsmärkten nach Maßgabe des Vorkriegsstandes. Die Stimmung in Prag schien einem solchen Unternehmen im allgemeinen günstig: Das Außenministerium war, wie sich auf einer interministeriellen Besprechung am 28. März zeigte, nicht zuletzt aufgrund der häufigen Eingaben von Kammern und Verbänden einer Liberalisierung der Ausländerbeschäftigung wohlgesonnen. Belange der Staatssicherheit seien unerheblich; Arbeitsmarktprobleme ließen sich auch innerstaatlich regeln. Lediglich die Militärs warnten vor dem Einströmen „irredentistischer Elemente“ und fanden Verbündete im Fürsorgeministerium, das den Arbeitsmarktschutz aus sozialen Gründen für ungenügend erachtete. 25

Vor dem Hintergrund von Genf und Stockholm war die „Bestürzung “26 des Hauptverbands über die Regierungsvorlage ${ }^{27}$ vom 25 . Oktober 1927 nachvollziehbar. Diese

22 ÖStA, BAA, o.S., Gesandtschaft Prag an BAA, 26.10.1926.

23 PA, R 73 806, Gesandtschaft Prag an AA, 29.10.1926.

24 ČS vom 6. 12. 1926.

25 DHI, Tätigkeitsbericht 1927, S. 92 f. - Vaněk, Aufgaben. - BVMI 1927, S. 136. - SÚA, MSP, Karton 1102, E 1a/132, Protokoll der interministeriellen Besprechung am 28. 3.1927.

26 So charakterisierte der DHI seine Reaktion: Vgl. DHI, Tätigkeitsbericht 1927, S. 92 f.

27 TTZPS, 2. WP, Drucksache 1227/1927, verteilt in der Sitzung des Abgeordnetenhauses am 25. 10. 1927. 
verschlechterte - völlig unerwartet - die Rechtslage nicht unwesentlich: Die Beschäftigung eines Ausländers setzte nun eine Genehmigung durch die Politische Behörde zweiter Instanz voraus; Vorbedingung waren wichtige volkswirtschaftliche und $\mathrm{Ar}$ beitsmarktinteressen, insbesondere das Fehlen inländischer Kräfte sowie schwerwiegende soziale Gründe. Von der Bewilligungspflicht waren nur seit dem 1. Mai 1923 ununterbrochen im Land ansässige Personen ausgenommen. Genehmigungen waren befristet, sie galten ad personam und nur für ein bestimmtes Arbeitsverhältnis bzw. Unternehmen und konnten an weitere Bedingungen geknüpft werden. Möglich war eine Verlängerung auf Ansuchen des Arbeitgebers; dieser hatte auf Anforderung Auskünfte über die Gesamtlage der Ausländerbeschäftigung in seinem Betrieb zu erteilen.

Begründet wurde der Entwurf ausgerechnet mit den geschilderten Liberalisierungsbestrebungen unter der Ägide des Völkerbundes, welche - so hieß es - nun gerade eine Schärfung der innerstaatlichen Zulassungsinstrumente erforderlich machten, außerdem mit dringenden nationalökonomischen Bedürfnissen und ähnlich restriktiven Tendenzen des Auslands. Nun kann angesichts der damals keineswegs ungünstigen Arbeitsmarktlage in der Republik die Konkurrenz um knappe Arbeitsplätze schwerlich der Anlaß für diese Vorlage gewesen sein. Maßgeblich waren vielmehr die mit den internationalen Wirtschaftsentwicklungen verknüpften Turbulenzen: Die forcierte Auslandsexpansion deutscher Unternehmen in den guten Jahren der Weimarer Republik hatte in den nationaltschechischen Kreisen, deren Grundstimmung von der jederzeit virulenten Sorge um die Selbständigkeit und Handlungsfähigkeit der Nation geprägt war, eine Welle von Überfremdungsängsten zur Folge, als deren Korollar die „nationalen Verhältnisse" aufs Tapet kamen. Josef Winternitz, Direktor der Böhmischen Kommerzialbank, berichtete im Januar 1927 in der "Prager Presse" über seinen Besuch im Reich, wo er Zeuge des glänzenden, für die Tschechoslowakei allerdings Anlaß zu Besorgnis gebenden Wiederaufschwungs geworden war. Die Deutschen seien bei den Amerikanern, der Welt-Avantgarde der Rationalisierung, in die Lehre gegangen und würfen jetzt alles in die Waagschale, „um nach amerikanischen Methoden sich den Platz an der Sonne zu erobern “. ${ }^{28}$ Die wachsende deutsche Wirtschaftskraft im Zuge der Konzentrationswelle war in der ČSR Gegenstand aufmerksamer Beobachtung. ${ }^{29}$ Die nationaldemokratische „Národní politika“ bezichtigte Deutschland, Versailles auf dem Umweg über die Wirtschaft aushebeln zu wollen; Polen sei die gewaltsame Eroberung, der Tschechoslowakei zumindest die ökonomische Penetration zugedacht. ${ }^{30}$

Vor diesem Hintergrund sind verschiedentliche, in diesen Zeitraum fallende Anläufe einzuordnen, das deutsche oder österreichische Kapital in die Schranken zu weisen, also etwa des Tschechischen nicht mächtigen Unternehmensvorständen das Wort auf Hauptversammlungen zu verbieten. Anknüpfend an verschiedentliche journalistische Vorgeplänkel feuerte dann der „Venkov“, Stimme der tschechischen Agrarpartei, am 2. Juli ${ }^{31}$ eine Breitseite auf die angeblich planmäßige, mit allen Machtmitteln, nicht zuletzt mit

28 Winternitz, Konzentration.

29 Das Prager Tagblatt berichtete von hundert Unternehmenszusammenschlüssen in Deutschland im ersten Halbjahr 1926: Vgl. PT vom 4.6.1927.

30 BArch-B, RMWi, Gesandtschaft Prag an AA, 31. 8. 1927.

31 Venkov vom 2.7.1927. 
Unterstützung amerikanischen Kapitals ${ }^{32}$, vorgetragene Offensive deutscher Großkonzerne ab, der zu begegnen die Tschechoslowakei nur mit Hilfe der Staatsmacht imstande sei. Die neuerliche Welle der Kritik an einer Expansion, die nicht nur Kapital, sondern auch Verwaltungsräte, Direktoren, Ingenieure und Werkmeister, ja sogar Arbeiter mit sich führe, hatte die Übernahme der tschechischen Firma Kř̌žik durch Siemens ausgelöst. ${ }^{33} \mathrm{Daß}$ der Konzern im Herzen von Prag, am Wenzelsplatz, domizilierte, markierte die symbolische Seite des Skandals. Deutsches „Kriegsziel“ sei, über die bestehende Hegemonie in der Kohle und in der Chemie hinaus, die Kontrolle der gesamten verteidigungswichtigen Industrie - die dort nistenden reichsdeutschen Geheimnisträger machten - so hieß es - den Kampfwert der Armee bereits zunichte. Die Offensive werde durch die deutschen Geldinstitute in der Tschechoslowakei unterstützt, aber auch die moralisch korrumpierten, profitsüchtigen tschechischen Banken leisteten der Okkupierung führender Positionen durch Reichsdeutsche keinen Widerstand.

In der vom Schlachtruf des "Venkov" ausgelösten, sich bis in den Herbst hineinziehenden Pressedebatte waren je nach politischer Observanz unterschiedliche Töne zu hören: Der Leitartikler des "Sozialdemokrat" tat am 5. August den Ausfall als Kampf gegen Windmühlenflügel ab; nach Auffassung der deutschen Sozialdemokraten lenkte die nationale nur von der sozialen Frage ab. ${ }^{34}$ Der Naivität, ja Heuchelei bezichtigte "Rudé právo" die Agrarpartei: Sie hause mit den Deutschen in der Regierung, in Banken und Aufsichtsräten kommod zusammen und suche durch derlei Pressegeplänkel ihrer eigenen Expansion ein Mäntelchen umzuhängen..$^{35}$ "České slovo" griff den Faden schon deshalb auf, um zu demonstrieren, daß die Volkssozialisten der agrarischen Konkurrenz in nichts nachstünden ${ }^{36}$; das Blatt häufte Schande auf die profitgierigen tschechischen Banken und die Konnationalen, die im Zuge der Nostrifizierung als Strohmänner in die Verwaltungsräte eingetreten seien und erst durch die patriotischen Parteien an ihre Pflicht und Schuldigkeit erinnert werden müßten. Das reichsdeutsche Element - daran könnten auch die "talmudischen Erklärungen“ der "Bohemia“ nicht rütteln - sei ein Fremdkörper im Organismus der Nation. Diese Invektive war ein Seitenhieb gegen die harsche Replik der „Bohemia “ gegen den "nationalen Primitivismus" des „Venkov“: dieser stilisiere die Entwicklung in der Elektroindustrie und eine Handvoll deutscher Ingenieure in der Poldihütte und dem Aussiger „Verein für chemische und metallurgische Produktion " zur existentiellen Bedrohung des Staates hoch und schlage je nach Bedarf inländisch-deutsches oder "national indifferentes Kapital “ dem reichsdeutschen zu. Die Deutschen, so Bacher in der „Bohemia“, investierten Know-how und Patente, sie stellten ihre technische und kommerzielle Organisation zur Verfügung und retteten nicht zuletzt viele marode tschechische Unternehmen und gefährdete tschechische Arbeitsplätze. Zwar sei dies keine philanthropische Tat, sondern zeuge von gesundem Geschäftsgeist; immerhin aber enthalte man sich strikt politischer Einmischung und wahre streng die Legalität. Der tschechische Deutschenhaß werde aus Gründen politischer

32 Holtfrerich schätzt die Beteiligung der USA am gesamten Nettokapitalimport Deutschlands zwischen 1924 und 1930 auf 9,5 bis 10 von 18,2 Mrd. RM: Vgl. Holtfrerich, Kapitalexport, S. 135.

$33 \mathrm{Vgl}$. zum Hintergrund LNN vom 10.9.1927.

34 Der Sozialdemokrat vom 5. 8. 1927.

35 Rudé právo vom 11.8.1927.

36 Dies war zumindest die Interpretation der deutschen Gesandtschaft: Vgl. BArch-B, RMWi, 2895, Gesandtschaft Prag an AA, 5. 8.1927. - ČS vom 6. und vom 29. 8. 1927. 
Opportunität ab und an in die Ecke gestellt - bei Anlässen wie dem aktuellen jedoch luge "der Pferdefuß regelmäßig wieder hinter den Frackschößen hervor“. Hauptziel der Polemik sei die Einschüchterung der Deutschen mit dem Ziel, Tschechen in wichtige Positionen zu hieven. Die Betroffenen, so Bachers Warnung, hätten aber kein Verständnis für die nationalpolitischen Finessen der Agrarpartei und würden über kurz oder lang dem Land den Rücken kehren. ${ }^{37}$

Das Echo auf den Entwurf vom 25. Oktober war vielstimmig: Die Handelskammerzentrale ${ }^{38}$ begrüßte einerseits zwar die solidere Fundierung des Arbeitsmarktschutzes. Das Gesetz sei zumindest als Druckmittel bei zwischenstaatlichen Verhandlungen keineswegs überflüssig; wenn der Tschechoslowakei auch an freien internationalen Austauschbeziehungen gelegen sein müsse, so doch nur im Sinne eines Fernziels. Die Zentrale warnte im gleichen Atemzug jedoch vor einer Fachkräftemangel produzierenden Überregulierung und rief nach einem unbürokratischen Verfahren unter Einschaltung von Kammern und Verbänden und bei reduzierten Gebühren. Wesentlich schroffer war die Opposition des Mährischen Industriellenverbandes und des Deutschen Hauptverbands der Industrie, dessen Arbeitgeberausschuß am 22. November nicht weniger als die Einstampfung des Entwurfs verlangte. $\mathrm{Zu}$ ebenso einmütiger Ablehnung war am 6. Oktober der Zentralausschuß der tschechoslowakischen Industrie unter der Regie Hodáčs, des Sekretärs des slowakischen Industriellenverbandes und der Vertreter des Mährisch-Ostrauer Industriellenverbandes gelangt. Das geltende Recht, so die Unternehmerverbände unisono, sei drückend genug; die Absperrung des Arbeitsmarktes schreibe, ähnlich wie die hohen Zollmauern, die protektionistische Nachkriegspraxis fest. Die arbeitsmarktpolitische Ratio des Gesetzes, die seine politischen Motive nur bemäntle, sei widersinnig, da die Arbeitslosigkeit sich auf wenig qualifizierte Kräfte beschränke, Spezialisten hingegen gesucht und für die Durchführung der anstehenden Rationalisierungmaßnahmen unentbehrlich seien. Daß tschechoslowakische Staatsbürger im Ausland in größerer Anzahl beschäftigt seien als umgekehrt Ausländer in der ČSR, mache diese erpreßbar. Der Hauptverband, der übrigens nicht zuletzt darauf verweisen konnte, daß alle Gewerkschaften bis auf eine tschechischnationale Angestelltenvereinigung ein Schutzgesetz ablehnten, hieß auch den großen Spielraum, den die Bewilligungskriterien dem freien Ermessen ließen, nicht gut. Könne das Vorhaben nicht zu Fall gebracht werden, so seien zumindest die Grenzgänger und die in der ČSR bereits ansässigen Ausländer, zu Ausbildungszwecken in einen inländischen Unternehmensteil berufene leitende Angestellte und Arbeitnehmer ausländischer Firmen sowie die zur Bedienung ausländischer Spezialmaschinen erforderlichen Fachkräfte von der Geltung des Gesetzes auszunehmen. Gefordert wurde eine Reduzierung der Formalitäten, eine erhebliche Milderung der Strafbestimmungen, die obligatorische Erledigung von Gesuchen binnen zwei Wochen, die Verankerung des ordentlichen Rechtswegs bei Ablehnung, die Festlegung niedrigerer Gebühren - bis maximal 50 Kronen pro Jahr - im Gesetz selbst, die Anhebung des Bewilligungszeitraums auf mindestens fünf Jahre im Regelfall und die Möglichkeit der Verlängerung auf formlosen Antrag hin. Das Gesetz sollte überhaupt nur bei ungünstiger Arbeitsmarktlage vom Ministerium für soziale

$37 \mathrm{BO}$ vom 4. 8. 1927.

38 BArch-B, RMWi, Karton 2896, Stellungnahme der tschechoslowakischen Handels- und Gewerbekammerzentrale, undat. 
Fürsorge im Benehmen mit dem Handels- und dem Landwirtschaftsministerium, dem Ministerium für öffentliche Arbeiten sowie den gewerkschaftlichen und unternehmerischen Spitzenverbänden temporär in Kraft gesetzt werden können. ${ }^{39}$

Presse und Öffentlichkeit waren angesichts des Entwurfs geteilter Meinung. Stellte der "Venkov" nach wie vor den Schutzgedanken in den Vordergrund ${ }^{40}$, so wurde in den "Národní listy“ der typische Zwiespalt der Nationaldemokraten zwischen Nationalismus und industrieller Interessenbindung offenkundig: Befürwortete am 4. Dezember das Organ eine liberale Regelung für Spezialisten bzw. zumindest einen Kompromiß zwischen den Belangen der Wirtschaft und denen der einheimischen Arbeitskräfte, so hatte der "Národ“, das zugehörige Abendblatt, bereits am 16. September anhand des Beispiels der Siemenstochter „Elektrotechna" die Behörden der Passivität angesichts der "Großeinfuhr" deutscher Staatsbürger geziehen. ${ }^{41}$ Im Opponentenlager gerieten in der Folgezeit auch die undemokratischen Arkanpraktiken des parlamentarischen Procedere ins Visier: „Entgegen aller Gepflogenheit“, so der $\mathrm{DHI}^{42}$, sei der Entwurf sofort an den sozialpolitischen Ausschuß des Abgeordnetenhauses weitergeleitet worden; nicht einmal den Koalitionsparteien sei Gelegenheit zur Stellungnahme gegeben worden. „Wenn bei der vollkommenen Übereinstimmung der Ansichten aller Betroffenen trotzdem an dem nunmehrigen Regierungsentwurfe nichts mehr soll geändert werden (!), so wäre dies wieder einmal charakteristisch dafür, in welcher Weise bei uns Gesetze gemacht werden, die die Unternehmer und Arbeitnehmer belasten ... Es wäre hoch an der Zeit, daß von dieser eigenartigen Verhandlung von Wirtschaftsangelegenheiten abgegangen würde." Tatsächlich war der Entwurf im sozialpolitischen Ausschuß am 25. und 26. Januar 1928 im Schnellverfahren und unter Ablehnung aller Einwände durchgenommen worden. ${ }^{43}$ Das Parlament werde, so die Arbeitgeberhauptstelle des DHI, „zu einer Abstimmungsmaschine ohne Willen“ degradiert. ${ }^{44}$

Konnte sich die Regierung auch, wie der prominente, in Arbeitsmarktfragen versierte deutsche Jurist und Nationalökonom Rauchberg betonte, keineswegs auf den einmütigen Willen von Arbeitgebern und Gewerkschaften berufen ${ }^{45}$, so handelte sie doch unzweifelhaft im Sinn des Nationalrats, welcher bereits im Vorfeld des Regierungsentwurfs, am 19. September 1927, eine Revision des Genehmigungsverfahrens angemahnt hatte. Der Nationalrat setzte auch die Parlamentsfraktionen von seinen Forderungen in Kenntnis; im Januar 1928 arbeitete seine volkswirtschaftliche Kommission ein Memorandum für die Abgeordneten aus. ${ }^{46}$ Das Abgeordnetenhaus nahm denn auch die Vor-

39 MDHI 8 (1927), S. 92 f. - Kotrba, Ausländer. - DHI, Tätigkeitsbericht 1927, S. 92-94. - BVMI 1927, S. 134f. - BArch-B, RMWi, 2895/1, Deutsches Konsulat Reichenberg an Gesandtschaft Prag, 10.10.1927. - PA, IIb, Wirtschaft 10, Tschechoslowakei, Band 2, Deutsches Konsulat Brünn an AA, 23. 2. 1928.

40 Venkov vom 3.12.1927.

41 NáL vom 4.12.1928. - NáL/Abendblatt Národ vom 16. 9.1927.

42 MDHI 9 (1928), S. 104 f.

43 APČR, PSSA, Sitzung des sozialpolitischen Ausschusses am 25. und am 26.1.1928. - Zum Abschluß der Bericht des sozialpolitischen Ausschusses, TTZPS, Drucksache 1439 vom 26.1. 1928.

44 SÚA, MSP, Karton 1586, E 2/a-2/1, Manuskript Rudolf Ferneggs, des Leiters der Arbeitgeberhauptstelle: „Der angebliche Schutz des heimischen Arbeitsmarktes“, auch veröffentlicht in der BO vom 29. 1.1928.

45 Rauchberg, Schutz.

46 SÚA, MSP, Karton 1586, E 2/a-2/1/1927-28, Tschechoslowakischer Nationalrat an MZV, 19. 9. 1927. - Vgl. auch SÚA, NRČ, N, Karton 414, Bericht über die Aktivitäten für die Sitzung 
lage mit nur wenigen Abmilderungen von Belang an: Das Ministerium für soziale Fürsorge wurde ermächtigt, vor dem Hintergrund der jeweiligen Arbeitsmarktslage nach Anhörung der Spitzenverbände und im Einvernehmen mit den einschlägigen Ressorts die Anwendung auszusetzen. Ermöglicht wurde die Herausnahme von Tätigkeiten aus dem Geltungsbereich des Gesetzes. Für die Beschäftigung ausländischer Staatsangehöriger konnten Bedingungen analog denen, welchen tschechoslowakische Bürger in den jeweiligen Heimat-Staaten unterworfen waren, statuiert werden. Mit diesen Modifikationen trat das Gesetz über den Schutz des heimischen Arbeitsmarktes am 13. März 1928 in Kraft. ${ }^{47}$

Die Durchführungsrichtlinien unterschieden zwei Gruppen von Betroffenen: Zum einen Personen, die vor dem 1. Mai 1923 in die ČSR eingereist waren und sich seitdem ununterbrochen dort aufhielten; kurzfristige, durch persönliche bzw. Familienangelegenheiten begründete Unterbrechungen des Aufenthalts von bis zu drei Wochen pro Jahr beeinträchtigten ihren Status nicht. Zur zweiten Gruppe rechneten diejenigen Ausländer, die nach dem 1. Mai 1923 zugereist waren oder ihren Aufenthalt seitdem unterbrochen hatten; sie benötigten eine von der Politischen Behörde zweiter Instanz in der Regel für ein Jahr, „stets aber nur für die dringendste Zeit" ausgefertigte Anstellungsgenehmigung. Bereits erteilte Bewilligungen blieben in Kraft. Die Gebühren bemaßen sich zwischen 20 und $1000 \mathrm{Kronen}^{48}$, je nach dem Umfang und dem Schwierigkeitsgrad der Verhandlungen und den dadurch verursachten Kosten, der Bedeutung der Angelegenheit, dem Vorteil für den Antragsteller sowie dessen Vermögensverhältnissen. Im konkreten Fall richtete sich die Höhe nach dem Dienstrang des Angestellten und der Geltungsdauer der Bewilligung: Direktoren und leitende Ingenieure wurden mit Beträgen zwischen 800 und 1000 Kronen belastet, Fachbeamte, Meister und Werkführer waren im Korridor zwischen 600 und 800 Kronen, untere Beamte zwischen 400 und 600 , Facharbeiter zwischen 200 und 400, unqualifizierte Arbeiter und Lehrlinge zwischen 100 und 200 Kronen eingestuft. Bei kleineren Betrieben oder solchen in schlechten wirtschaftlichen Umständen waren die Behörden gehalten, sich an der unteren Grenze zu bewegen, bei stagnierenden oder wirtschaftlich angeschlagenen Unternehmen sowie in Fällen, in denen ein Ausländer zur Einführung eines neuen Produktionszweiges benötigt wurde, konnte der Satz sogar unterschritten werden. ${ }^{49}$

Nicht stattgegeben wurde im Fürsorgeministerium der prompt, noch im März, vorgetragenen Forderung der Konföderation der Tschechoslowakischen Arbeitgeberverbände, die Anwendung des Gesetzes zu stornieren. ${ }^{50}$ Auf seiner Sitzung am 20. April mußte der Arbeitgeberausschuß dann bereits eine deutlich rigidere Verwaltungspraxis konstatieren. Auch der Mährische Industriellenverband sah seine Befürchtungen bewahrheitet. Daß etwa die Gebühren für gehobene Angestellte durchwegs nahe der oberen Grenze angesetzt wurden, war Anlaß zahlreicher Interventionen des DHI. Das Fürsorgeministerium stellte sich taub gegen eine ganze Reihe vom Hauptverband mit-

der Volkswirtschaftlichen Kommission am 17.2. 1928. - Bericht über die Tätigkeit der Volkswirtschaftlichen Kommission für die Sitzung am 29.11.1928.

47 DHI, Tätigkeitsbericht 1927, S. 92-94. - MDHI 9 (1928), S. 323.

48 Nach den Gesetzen Nr. 453 /1925 bzw. 253/1926 und 254/1926.

49 MADTV 10 (1928), S. 89. - Originaltext des Erlasses vom 23. März in: MDHI 9 (1928), S. 473 f.

50 SÚA, MSP, Karton 1807, E 4/a/1930, Konföderation der tschechoslowakischen Arbeitgeberorganisationen an MSP, 27.3.1928. - MSP an die Konföderation, 24. 4. 1928. 
getragener Sistierungsanträge des Zentralverbands; im Sommer mußte der DHI das Amt gar um ein Lebenszeichen ersuchen. Pikanterweise erreichte zwischen Juni und September 1928 die Arbeitslosigkeit den seit Beginn der Erfassung durch das Statistische Staatsamt niedrigsten Stand überhaupt. ${ }^{51}$ Angesichts dieser außerordentlich günstigen Arbeitsmarktlage, so konnte der DHI nun nachtarocken, sei es „pure Heuchelei“, das von „engherzigem Polizeigeist“ erfüllte Gesetz „als Fürsorge für den inländischen Arbeiter zu bezeichnen ${ }^{452}$ - Heuchelei vor allem auch angesichts des sich verstärkenden internationalen Trends zur Liberalisierung der grenzüberschreitenden Arbeitsmarktbeziehungen, wie er sich am Beispiel der Übereinkunft zwischen Deutschland und Frankreich zeigte. ${ }^{53}$

Rauchberg wog zum wiederholten Male die Wichtigkeit des „Lernens im Ausland“ für die tschechoslowakische Wirtschaft gegen die quantité négligeable der Zuwanderung einer kleinen Zahl von Spezialisten ab. Die ČSR beute diese durch die Gebührenregelung fiskalisch aus und nutze die Gelegenheit, das „Abschließungsregime“ durch „Vollmachten an die mit der Durchführung betrauten Behörden zu verschärfen, die nicht nur überflüssig und unerträglich, sondern auch mit dem Wesen des Rechtsstaats unvereinbar" seien. ${ }^{54}$ Eine andere prominente Stimme aus deutschen Wirtschaftskreisen, der Direktor der Prager Brown-Boveri-Werke, Paul Eisner, stufte das Gesetz als Dauerregelung zur Bekämpfung lediglich temporärer und punktueller Mißstände ein, welche "Druck auf das Niveau des inländischen Wirtschaftsnachwuchses" bewirke und unter dem Einfluß extremer Nationalisten dem „Geist des Provinzialismus" analog zu der oft beklagten „Verlinzerung Wiens" Vorschub leiste. ${ }^{55}$

Aus Nützlichkeitserwägungen geborenen Vorbehalten begegnete eine Arbeitsmarktpolitik im nationalistischen Geist aber auch in tschechischen Wirtschaftskreisen: Im Juli 1928 kritisierte der Wirtschaftsjournalist Gustav Stern ${ }^{56}$ in der "Tribuna“ die von dem Prager Professor für Volkswirtschaftslehre Cyril Horáček zum wiederholten Male vorgetragenen Pläne zu einer Nationalisierung der Industrie. ${ }^{57}$ Für angebracht erachtete Stern dies, weil es sich bei Horáček immerhin um ein prominentes Mitglied von Masaryks einstiger Realistenpartei handelte; der Professor hatte nach dem Krieg der Agrarpartei, ab Mitte des Jahrzehnts den Nationaldemokraten nahegestanden, er war 1919 in der Regierung Tusar zeitweilig Finanzminister gewesen und galt nach wie vor als ministrabel.$^{58}$ Horáčeks Vorschlag, mittels eines Pluralstimmrechts der tschechischen Aktionäre den Tschechen verstärkt Zugang in die Verwaltungsräte zu bahnen, tat Stern als Pseudo-Nationalisierung ab: Zumindest die Zusammensetzung der - lokal gebundenen

51 MDHI 9 (1928), S. 403, 502, 835 f., 983. - BVMI 1928, S. 120 f. - OB 10 (1928), S. 217 f.

52 MDHI 9 (1928), S. 984. - Die Kritik des Verbands über die - auch von den Gewerkschaften abgelehnte - „engherzige Haltung unseres Ministeriums für soziale Fürsorge“ war auch im Herbst nicht verstummt: Vgl. Reichenberger Zeitung vom 19.11.1928.

53 MDHI 9 (1928), S. 739.

54 Rauchberg, Schutz.

55 Eisner, Schutz.

56 Angaben zur Person waren nicht zu ermitteln.

57 Gemeint war die jüngste Nummer der „Steuer- und Bilanzrevue“ (Daňová a bilanční revue). Mit ähnlichen Gedankengängen hatte ein pseudonymer Autor, hinter dem Stern ebenfalls Horáček vermutete, den Jahrgang 1924 des „Obzor národohospodářský“ eröffnet: Vgl. ONH 29 (1924), S. 1-5.

58 Horáček lebte von 1862 bis 1938: Vgl. ČBS, S. 226. - ČDD, S. 327. 
- Arbeiterschaft sei auf diesem Wege nicht zu ändern. Die entscheidende Barriere auf dem Weg zu einer Umschichtung der "nationalen Verhältnisse“ erblickte Stern in dem Umstand, daß die Direktion die Schaltzentrale eines modernen Betriebs darstellte und für diese Ebene eine tschechische Personalreserve schlichtweg nicht existierte. Nun war auch Stern keineswegs im Grundsatz gegen eine Änderung der „nationalen Verhältnisse“; er empfahl jedoch, vorerst Beunruhigung zu vermeiden und das Ruder den „lieben deutschen Mitbürgern" zu überlassen. ${ }^{59}$ Rücksicht auf Recht und Gerechtigkeit, so die deutsche Reaktion, hätten die Tschechen sicherlich nicht von Nationalisierungsgesetzen abgehalten, „wenn sie nicht befürchten müßten, daß die plötzliche Ausschaltung des Deutschtums die Vernichtung der unersetzlichen Seele der Unternehmungen bedeuten würde". Die Industrie habe keinen Anlaß, sich in Sicherheit zu wiegen, nur weil Horáčeks Vorschläge im Augenblick nicht durchführbar seien..$^{60}$

Diese Prognose bewahrheitete sich unverzüglich, als am 5. September die MährischOstrauer „Morgenzeitung und Handelsblatt“ von einem Spionagefall berichtete. In diesem Zusammenhang war ein früherer Beamter des Witkowitzer Eisenwerks, ein Reichsdeutscher, verhaftet worden. Die Meldung sei, so die Vermutung der Deutschen Paßstelle Mährisch-Ostrau, Stimmungsmache gegen Deutschland - wohl eine erfolgreiche, weil beim nordmährisch-schlesischen Industriellenverband viele befremdete Anfragen aus deutschen industriellen Kreisen eingingen. ${ }^{61}$ Der Kulminationspunkt aber wurde im Oktober, fristgerecht zum zehnjährigen Staatsjubiläum, auf einer Delegiertenversammlung der tschechischen Agrarpartei in Budweis erreicht. Rudolf Beran, der Generalsekretär der Partei, tönte, „hunderttausende tschechischer Arbeiter in unserer freien Republik" seien "noch Sklaven fremden Kapitals“. ${ }^{62} 1918$ sei die Lösung des drängendsten Problems versäumt worden: Die „Nationalisierung unserer Industrie“ unter energischer Beteiligung der tschechischen Banken und des Staates - „damit die zeitweisen Konjunkturen nicht nur für Angehörige fremder Staaten, die bei uns Industrieobjekte besitzen, eine Quelle der Kapitalsanhäufung bilden". Aus diesem Grund solle das Recht von Ausländern, „führende Stellen in den Verwaltungsräten wichtiger Unternehmungen " zu bekleiden, eingeschränkt und die Besetzung dieser Positionen mit tschechischen Patrioten vorangetrieben werden. ${ }^{63}$

Im Kielwasser dieser Polemik illustrierte der Leitartikel des „Venkov“ vom 20. Oktober am Beispiel von Kř́̌̌zik sowie anhand des Bergbaus und der Chemie, der Eisen-, der Textil- und der Zementindustrie wieder einmal den ausländischen, insbesondere deutschen Einfluß speziell in den verteidigungswichtigen Schlüsselindustrien. ${ }^{64}$ Dieser

59 Stern, Glossen.

60 PA, Gesandtschaft Prag, I/1c, Band 1, Redakteur F. Winkler, Rundschreiben an die Presse vom 30.7.1928.

61 PA, R 89 715, Deutsche Paßstelle Mährisch-Ostrau an Gesandtschaft Prag, 26. 9. 1928.

62 Diese Verbindung stellt zumindest das Berliner Tageblatt vom 24. 10. 1928 her.

63 Zum Inhalt der Rede, die im Originaltext nicht ermittelt werden konnte, vgl. PA, R 89745 , Gesandtschaft Prag an AA, 19. 10.1928. - WI 10 (1928), S. $1283 \mathrm{f}$.

64 Venkov vom 20.10.1928. - Vgl. in diesem Zusammenhang etwa auch den Überblick der Deutschen Paßstelle Mährisch-Ostrau über die Meinungstrends in der tschechischen Presse: Dort werde zwar eine langsame Besserung in der Frage der "nationalen Verhältnisse“ konstatiert; es bleibe aber noch genug zu tun. Zielscheibe der Angriffe sei etwa das Eisenwerk in Trinec wegen des großen deutschen Einflusses in der Leitung. Die Ernennung eines französischen Direktors habe die tschechische Presse mit Jubel begrüßt, nur um später enttäuscht festzustellen, er sei 
Posaunenstoß war „lediglich die Ouvertüre zu einer systematischen Aktion der tschechischen Agrarpartei “65: Ein Beschluß des Parteipräsidiums forderte das für die Zulassung von Gesellschaften, die Genehmigung von Statutenänderungen bzw. Kapitalerhöhungen zuständige Innenministerium auf, ein Gesetz im Sinne Berans vorzulegen. Das Präsidium selbst beauftragte eine Kommission mit der Ausarbeitung eines Entwurfs, der in all diesen Fällen behördliche Bewilligungen an nationalpolitische Bedingungen und Auflagen knüpfte. Berans Ausfälle, so der Kommentar der Prager Gesandtschaft, seien einerseits auf den reichsdeutschen, andererseits, wie der Begriff der „Nationalisierung" zeige, nun aber bereits auch auf den Einfluß der einheimischen Deutschen in der Wirtschaft der Tschechoslowakei gemünzt. Sie seien „charakteristisch für den Geist, der die führenden Persönlichkeiten der tschechischen Politik auch jetzt noch beherrscht, nachdem sie bereits zweieinhalb Jahre mit sudetendeutschen Parteien in einer Regierungskoalition sitzen“. Die ČSR stelle sich „tief unter den Balkan..., wo Fragen des ausländischen Einflusses und Kapitals wohl in erster Linie nach Zweckmäßigkeitsgründen und nicht von nationalistischen Gesichtspunkten aus erledigt werden ${ }^{\text {" }}{ }^{66}$ Beran provoziere, so der Hauptverband aus dem ökonomischen Blickwinkel, die Flucht des ausländischen Kapitals und den Verlust zahlreicher unentbehrlicher Arbeitskräfte. ${ }^{67}$

Der Angriff, welcher „wie eine Bombe in den mühsam behaupteten Jubiläumsfrieden hineingeplatzt war ${ }^{468}$, fand sogleich Bundesgenossen: Der Nationalrat wies seine volkswirtschaftliche Kommission an, mit der Agrarpartei die Gesetzgebung zur Korrektur der "nationalen Verhältnisse" abzusprechen. ${ }^{69}$ In einer erregten Pressedebatte stritten die "Národní listy“ die Notwendigkeit einer besonnenen Nationalisierung mit langem Atem keineswegs ab, warnten als führendes Industrieblatt jedoch eindringlich vor Eskapaden à la Beran welche im deutschen Reich etwa die "Vossische Zeitung“ an die Bodenreform erinnerten. ${ }^{70}$ Führende Politiker der tschechischen Agrarierpartei ließen nach einer Intervention des deutschen Ministers Spina vom Bund der Landwirte von diesem zwar die Existenz des Präsidialbeschlusses dementieren; bemerkenswerterweise ergriff jedoch keine Persönlichkeit aus der obersten Etage der Partei das Wort. Ebensowenig zogen die der Agrarpartei nahestehenden "Večer" und "Venkov" die Nachricht zurück. Die Führungsriege der Partei verschanze sich - so die Mutmaßung der deutschen Gesandtschaft - hinter ihrer Anonymität, und die tschechische Presse suche die seit Rašín gehegten, komplementär zur Bodenreform und zur Arbeitsmarktgesetzgebung ventilierten Nationalisierungsprojekte - „lang gehegte Pläne der führenden Köpfe

„vollständig im Fahrwasser der Pangermanisten und polnisch-sozialistisch-kommunistischen Elemente" und "gegen alle tschechischen Bestrebungen eingenommen": Vgl. PA, R 73 834, Deutsche Paßstelle Mährisch-Ostrau an AA, 24. 10.1928.

65 PA, R 89 746, Gesandtschaft Prag an AA, 23.10.1928.

66 PA, R 89 745, Gesandtschaft Prag an AA, 19. 10. 1928. - PA, R 89746 , Gesandtschaft Prag an

AA, 23. 10. 1928. - Daß mit den "Ausländern“ in erster Linie Reichsdeutsche und Österreicher gemeint seien, war auch die Auffassung der "Wirtschaft": Vgl. WI 10 (1928), S. $1283 \mathrm{f}$.

67 MDHI 9 (1928), S. $921 \mathrm{f}$.

68 Tagesbote (Brünn) vom 25. 10.1928.

69 SÚA, NRC, N, Karton 413/2/236-7, Sitzung der Volkswirtschaftlichen Kommission am 18. 10.1928.

70 VZ vom 25. 10.1928. - Vgl. zum reichsdeutschen Presseecho auch Berliner Tageblatt vom 24. 10. 1928. - Berliner Lokal-Anzeiger vom 25. 10.1928. - Deutsche Allgemeine Zeitung vom 26. 10. 1928. 
der tschechischen Agrarpartei" - nun sogar den einheimischen Deutschen schmackhaft zu machen, die von einem Abzug der Reichsdeutschen profitieren würden; einzige Frage sei, ob man bereits über die nötige Kapitalmacht verfüge. Habe man sich aufgrund der eindringlichen Warnungen der Presse vor den ökonomischen Konsequenzen einer solchen Aktion und verschreckt von den potentiellen internationalen Verwicklungen sowie durch die hektische Reaktion der Börse einstweilen auch zurückgezogen, so sei das Streben nach der „volkswirtschaftlichen Autarkie unter möglichster Ausschaltung nicht bloß des ausländischen deutschen und österreichischen, sondern auch des sudetendeutschen Kapitals" doch nach wie vor virulent und werde wohl „früher oder später mit gewissen Erfolgen gekrönt werden " ${ }^{71}$ Schließlich handelte es sich, wie Bacher besorgt sekundierte, bei den Agrariern um die größte und mächtigste tschechische Partei. Bacher lobte in der "Wirtschaft" den Hauptverband für seine postwendende Reaktion und forderte ein deutliches Wort auch des Zentralverbands für das Ohr des Auslands, wo die ČSR, welche die „Verbindungen mit den technischen und auch mit den kapitalistischen Befruchtungsquellen" suchen müsse, wegen ihrer "übertriebenen merkantilistischen Politik" bereits in zweifelhaftem Ruf stehe und wo man nicht länger bereit sei, „xenophobe Extratouren einfach als die Ausbrüche des kindlichen Größenwahns eines jungen, sich seiner Kraftgrenzen und seiner Stellung in der Welt und auch seiner zahlreichen natürlichen Abhängigkeiten noch nicht bewußt gewordenen Staatswesens mit einem verzeihenden Lächeln abzutun" ${ }^{72}$

Nun versicherte Außenminister Beneš dem deutschen Gesandten in Prag andererseits, chauvinistischen Bestrebungen, Ausländer von leitenden Positionen in der Wirtschaft fernzuhalten, werde "keinesfalls" nachgegeben. ${ }^{73}$ In der Folge stufte die halbamtliche „Prager Presse“ die Phrase von "Nationalisierung der Industrie“ als probate Wahlkampfparole der Agrarpartei ein, deren Zugkraft mit den in- und ausländischen Protesten und den darauf folgenden Dementis jedoch dahingeschwunden sei. Auch die österreichische Botschaft und Beobachter des Deutschen Industrie- und Handelstages gaben zumindest für die nächste Zukunft Entwarnung, wenn sie längerfristig eine Offensive der Agrarpartei gegen die Industrie auch weiterhin für wahrscheinlich hielten. ${ }^{74}$ Praktische Konsequenzen ergaben sich jedenfalls nicht; die Arbeitsmarktpolitik steuerte im Gegenteil gerade in den folgenden Monaten auf einen Accord mit Deutschland zu. Zum Verständnis dieser Entwicklung ist ein Rückblick auf einen parallel zur Geschichte des Arbeitsmarktgesetzes verlaufenden Ereignisstrang erforderlich: die Entwicklung der Wirtschaftsbeziehungen zum Reich seit Anfang 1927.

Seit dem Frühjahr 1927 standen die Arbeitsmarktbeziehungen, die der deutsch-tschechoslowakische Wirtschaftsvertrag vom Juni 1920 ausgespart hatte, auf der Tagesordnung bilateraler Handelsvertragsverhandlungen. Ein erster Vertragsentwurf garantierte Ausländern wie Inländern gleichermaßen unbehinderte berufliche Tätigkeit. Ziel der ČSR war die Inkorporierung der Abmachung von 1923 in die Handelsvereinbarung;

71 PA, R 89 746, Gesandtschaft Prag an AA, 26.10.1928. - PA, Gesandtschaft Prag, A III/8, Band 2, Gesandtschaft Prag an AA, 28.10.1928. - Vgl. zu den Abläufen auch: ÖStA, BAA, Zl. 128/Pol., Österreichische Gesandtschaft Prag an Bundeskanzler Seipel, 31. 10. 1928.

72 Bacher, Fremden.

73 BArch-B, RMWi, 2896, Mitteilung AA an Reichswirtschaftsministerium, 12.11. 1928.

74 ÖStA, BAA, Zl. 128/Pol., Österreichische Gesandtschaft Prag an Bundeskanzler Seipel, 31. 10. 1928. - PA, R 89 746, Geschäftsführung des DIHT an die Mitglieder, 14.11. 1928. 
der bevorzugten Behandlung deutschstämmiger Tschechoslowaken durch die Reichsbehörden sollte ein Ende gesetzt werden. Hinzu kam, daß die Regelung von 1923, die Ausweisungen aus arbeitsmarktpolitischen Gründen nicht zuließ, zwar die günstigste von Deutschland einem Vertragspartner je konzedierte darstellte, ungeachtet dessen jedoch einer Nachbesserung bedurfte: Nach Ablauf eines Visums mußte nämlich durchwegs die Erneuerung beantragt werden. Hierdurch konnte das Ausweisungsverbot bequem ausgehebelt werden. Zudem unterlag im Reich die Materie dem Landesrecht und war deshalb sehr uneinheitlich geregelt.

Ende Juli 1927 war in einer Reihe von bilateralen Handelsfragen bereits eine Übereinkunft erzielt worden, während die Arbeitsmarktproblematik weiterhin kontrovers war. ${ }^{75}$ Die nach der Sommerpause im September wieder aufgenommenen Verhandlungen $^{76}$ gingen von der unstrittigen Notwendigkeit der Modifizienung des Vertrags von 1923 aus. Die am Stichtag des 30. April 1923 im Gebiet des Vertragspartners sich aufhaltenden Personen sollten keinen Einschränkungen beim Stellen- oder Beschäftigungswechsel unterliegen. Unterbrechungen des Aufenthalts für maximal sechs Wochen pro Jahr waren zulässig, nicht gerechnet vorübergehende, durch Militärdienst, Ausbildung, Dienstreisen u.ä. verursachte Abwesenheiten. Ablehnungen sollten einer Nachprüfung mit aufschiebender Wirkung unterzogen werden können. Offen blieben die Gebührenfrage $^{77}$ und die Frage der Beschäftigungsbewilligungen für Angestellte: War Deutschland bereit, diese ganz abzuschaffen, so insistierte in diesem Punkt die tschechoslowakische Delegation auf den bestehenden Beschränkungen. ${ }^{78}$

Die Handelsvertragsverhandlungen gelangten aus verschiedenen Gründen bald an einen toten Punkt und wurden Anfang November 1927 vorübergehend ausgesetzt. ${ }^{79} \mathrm{Ei}$ ner bilateralen Einigung auf dem Gebiet des Arbeitsmarkts abträglich waren innenpolitische Querschüsse aus der chauvinistischen Ecke: Unter Berufung auf eine Meldung der "Národní osvobozeni“" vom 12. Oktober, Siemens suche über die Reichsregierung von der ČSR eine „Sicherheitsgarantie“ für ihre Angestellten im Nachbarland zu erwirken, rügte eine Eingabe der Arbeitskommission der Beamten- und Angestellten-Werksausschüsse der Metallindustrie an das Ministerium für soziale Fürsorge die überaus hohe Anzahl Reichsdeutscher in der Branche im Grenzland. ${ }^{80}$ Während das Prager Außenministerium auf die Fortsetzung der Handelsvertragsverhandlungen drängte, hielt die Gegenseite, die auf eine Vereinbarung weniger dringend angewiesen war, das Junktim mit der Arbeitsmarktsübereinkunft aufrecht und verfuhr ansonsten dilato-

75 AMZV, Sektion IV, Karton 959, Mappe 2, Bericht Ibls vom 30. 7. 1927 über den Stand der tschechoslowakisch-deutschen Handelsvertragsverhandlungen Ende Juli 1927.

76 PA, II, Handel 13, Tschechoslowakei, Band 11, Windel an Eisenlohr, 5. 10.1927.

77 Die Tschechoslowakei wollte bei Angestellten auf folgenden Gebühren bestehen: Bei Jahreseinkommen bis 18000 Kronen sollten die Gebührensätze für Arbeiter gelten, bei Einkommen bis zu 30000 Kronen das Doppelte, bis 42000 Kronen das Dreifache, darüber hinaus bis zum Achtfachen.

78 AMZV, Sektion IV, Karton 964, Mappe 4, Bericht der Unterkommission vom 11.10.1927.

79 AA/Stresemann, an den Staatssekretär in der Reichskanzlei, 6.11.1927, in: ADAP, Serie B, Band VII, S. 175-177.

80 SÚA, MSP, Karton 1586, E 2/1-2/1/1927-28, Arbeitskommission der Beamten- und Angestellten-Werksausschüsse der Metallindustrie an MSP, 9.11.1927. 
risch. ${ }^{81} \mathrm{Am}$ besten sei es, so das Auswärtige Amt, die tschechslowakische Delegation den Komplex selbst anschneiden zu lassen. ${ }^{82}$ Mit dem vorläufigen, die Meistbegünstigung gewährenden Handelsvertrag vom Juni 1920 ließ es sich leben, weil er Deutschland ohnehin den ersten Platz unter den Importpartnern der ČSR einräumte und eine - vermutlich wenig bedeutende - Steigerung des deutschen Exports nicht sonderlich ins Gewicht fiel. ${ }^{83}$ Andererseits fühlte sich in der Frage der "Markprioritäten“ die deutsche Seite als Sachwalter der reichsdeutschen Besitzer dieser tschechoslowakischen Wertpapiere unfreundlich behandelt. ${ }^{84}$ Im Januar 1928 räumte Beneš in diesem Punkt ein, die bisherige Regelung sei untragbar ${ }^{85}$; dem reichsdeutschen Abgeordneten Lindeiner-Wildau versicherte er, Konzessionen seien zwar Grenzen gesetzt, ihm sei aber an einer befriedigenden Lösung gelegen. ${ }^{86}$

Die Verteilung der Trümpfe und Pressionsmöglichkeiten war also vergleichsweise komplex, als im Frühjahr 1928 die reichsdeutsche Presse das inzwischen verabschiedete tschechoslowakische Arbeitsmarktgesetz als "minderheitenfeindliche Regierungs- und Gesetzgebungspraxis in Prag", als ein "nicht nur gegen das deutsche Wirtschaftsleben im Staate, sondern gegen das Deutschtum überhaupt gerichtete(s) Attentat" aufgriff. ${ }^{87}$ Das Gesetz, eine nakute Gefahr für alle reichsdeutschen Direktoren, Ingenieure und kaufmännischen Angestellten “, biete „der tschechischen Regierung die Handhabe, morgen alle diese Reichsdeutschen auf die Straße zu setzen“, so daß die zuvor korrekten, ja freundschaftlichen Beziehungen jetzt „sehr einseitig auf Kosten des deutschen Reichs zu gehen" drohten. ${ }^{88}$ Angesichts der Erregung der Betroffenen und im Interesse der auf "vorgeschobenem Postn (!) “ des „Deutschtums“ sitzenden Inhaber leitender Stellungen forderte die Vereinigung der reichsdeutschen Vereine in der ČSR nach vergeblichen Versuchen, Öl auf die Wogen zu gießen, und ebenso fruchtlosen Interventionen die Gesandtschaft zu Gegenmaßnahmen auf, empfahl dem Reichsinnen- und dem Arbeitsministerium Retorsionen und suchte bei Reichsaußenminister Stresemann um eine Audienz an. Da der tschechischen Seite bewußt sei, daß es sich bei den meisten Betroffenen um Reichsdeutsche bzw. Österreicher handle, seien „wesentliche Bestimmungen“ des Gesetzes „als Ausnahmebestimmungen gegen Deutsche“ aufzufassen. Alteingesessene liefen Gefahr, aufgrund der Klauseln über die Aufenthaltsunterbrechung als Neueinwanderer behandelt zu werden, Betriebe würden aus Kostengründen auf

81 AMZV, Sektion IV, Karton 963, Mappe 4, č.j. 31 923/1929, Bericht des MZV für PMR. - Aktenvermerk MZV, beide undat.

82 PA, R 73 779, AA/Aufzeichnung für den Besuch des tschechoslowakischen Außenministers Beneš vom 19.5. 1928 .

83 PA, R 73 779, AA/Aufzeichnung zum Handelsvertrag, undat., für die Unterredung Schuberts mit Beneš im Mai 1928.

84 Vgl. Antrag Dr. Best, Seiffert, Dr. Roß und Genossen vom 13.3.1928, in: Reichstag, 3. WP, Drucksache 4070. - Vgl. zu den Abläufen und zu den „technicalities“ insbesondere auch: PA, R 73 779, Aufzeichnung Meyer-Rodehüser für die Unterredung des Herrn Staatssekretärs mit Minister Beneš, 13. 5. 1928.

85 PA, R 73 779, AA/Aufzeichnung zum Handelsvertrag, undat., für die Unterredung Schuberts mit Beneš im Mai 1928, mit Verweis auf einen Bericht Kochs vom 13. Januar 1928.

86 PA, R 73 779, AA/Aktenvermerk Bräuer vom 13.1.1928 über eine Unterredung mit dem Abgeordneten Lindeiner-Wildau nach dessen Pragreise vom 10. bis zum 12.1. 1928.

87 Neue Preußische Zeitung vom 21. 4. 1928.

88 MNN vom 20.4. 1928. - Vgl. auch die „Presseschau“ in: BArch-K, R 43/I, 150, Vertretung der Reichsregierung München an Reichskanzlei, 11.4.1928. 
ihre "gebührenpflichtigen" Angestellten verzichten, Arbeitgeber könnten mißliebige Angestellte über eine Zurückziehung der Aufenthaltsbewilligungen bequem loswerden. ${ }^{89}$

Mochte das Auswärtigen Amt gegen das Gesetz im ganzen auch „keine begründeten Einwendungen" erheben, so witterte man dort doch höchste Gefahr in den Bestimmungen über die Aufenthaltsunterbrechung: Viele "bessere“ Angestellte verbrachten nämlich einen Jahresurlaub von mehr als drei Wochen in Deutschland. Eine deutsche Verbalnote vom 25. April 1928 forderte deshalb die Anwendung der im vorangegangenen Herbst im Zuge der Handelsvertragsverhandlungen formulierten Richtlinien auch auf Angestellte sowie - die Gebührenfrage war damals ja offengeblieben - einen Verzicht auf die "Kopfsteuer". ${ }^{90}$ Anläßlich Benešs Besuch in Berlin im Mai ${ }^{91}$ tischte das Auswärtige Amt eine längere Reihe bilateraler wirtschafts- und finanzpolitischer Streitfragen auf, zu denen außer der Anwendung der Bodenreformgesetze auf reichsdeutsche Großgrundbesitzer und der Frage der "Markprioritäten“ auch „die Gefährdung und außerordentliche Beunruhigung der in der Tschechoslowakei in nichtselbständiger Stellung erwerbstätigen Reichsdeutschen" zählte. ${ }^{92}$ Bezeichnete Beneš gegenüber dem Staatssekretär im Auswärtigen Amt, Schubert, das Arbeitsmarktgesetz auch als fait accompli, so gab er doch in Anbetracht des Gewichts der Angelegenheit die Zusage, „wegen der administrativen Ausführung" die deutschen „Wünsche zu befriedigen“ ${ }^{93}$ Ende Juni ließ sich das Prager Außenministerium zu einer „beschleunigte(n) Erledigung“ der deutschen Aprilnote herbei ${ }^{94}$, so daß nach dieser Vorklärung mit einer baldigen Lösung gerechnet werden durfte. ${ }^{95}$ Nachdem eine "mit Genugtuung" zur Kenntnis genommene tschechoslowakische Note vom 31. Juli mit der Zusage aufgewartet hatte, Gesuche Reichsdeutscher, die die erlaubte Abwesenheitsdauer überschritten hatten, „mit weitgehendem Wohlwollen" zu behandeln, ging die deutsche Seite davon aus, solche Befreiungsanträge würden als Formsache behandelt und ohne weiteres genehmigt.

Steuerte das Auswärtige Amt in der "Unterbrechungsfrage" eine gütliche und „leise“ Einigung an und faßte Vergeltungsmaßnahmen nur als ultima ratio ins Auge, so verurteilte Emil Wällner, der Vorsitzende der Vereinigung der reichsdeutschen Vereine in der ČSR, anläßlich einer Vorsprache in Berlin solche Behutsamkeit als „unwürdig“: Die Reichsdeutschen wollten "wieder freie Männer" werden. Konsequent mahnten die Vereine "die schärfsten Maßnahmen" an. ${ }^{96}$ Für eine harte und unnachgiebige Haltung trat insbesondere der Hilfsverein deutscher Reichsangehöriger ein; dessen Vorsitzender, der

89 BayHStA, MA 103 108, Vereinigung der reichsdeutschen Vereine an AA, 23. 4. 1928. - Vereinigung der reichsdeutschen Vereine an Reichsinnenminister v. Keudell und Arbeitsminister Brauns, 25. 4. 1928.

90 SÚA, MSP, Karton 2946, E 4221 1928-9, Verbalnote der Gesandtschaft Prag an Außenministerium der ČSR vom 25. 4. 1928. - PA, R 73 779, AA/Aufzeichnung betreffend die Durchführung des tschechoslowakischen Gesetzes zum Schutz des Arbeitsmarktes vom 18. 5. 1928.

$91 \mathrm{Vgl}$. hierzu allgemein Campbell, Confrontation, S. $192 \mathrm{ff}$.

$92 \mathrm{PA}, \mathrm{R} 73$ 779, AA/Aufzeichnung für den Besuch des tschechoslowakischen Außenministers Beneš vom 19.5.1928.

93 PA, R 28 551, Aufzeichnung Schubert vom 24. 5. 1928.

94 SÚA, MSP, Karton 2946, E 4221 1928-9, Verbalnote der Gesandtschaft Prag an MZV, 30. 6. 1928.

95 SÚA, MSP, Karton 2946, E 4221 1928-9, Verbalnote der Gesandtschaft Prag an MZV, 30. 6. 1928.

96 PA, R 74 032, AA/Aufzeichnung Martius vom 31. 8. 1928. - BayHStA, MA 103 108, Vereinigung reichsdeutscher Verbände an AA vom 24. 9.1928. 
bayerische Staatsbürger Dr. Pflock, Chemiker, Angestellter des seit geraumer Zeit im Mittelpunkt der Agitation stehenden Aussiger „Vereins für chemische und metallurgische Produktion", intervenierte im Auswärtigen Amt sowie bei der Prager deutschen Gesandtschaft und berichtete dort laufend über Härte- und Skandalfälle. Am 28. Dezember 1928 schilderte Pflock dem bayerischen Ministerpräsidenten Held persönlich die Lage der Deutschen, unter denen sich eine nicht unbeträchtliche Anzahl von Bayern befand. Eine Denkschrift vom Januar 1929 legte dann dar, das Gesetz sei „in der Hauptsache gegen leitende reichsdeutsche Beamte gerichtet". Die von Beneš in Aussicht gestellte Kulanzregelung, derzufolge Ausländer mit „Freischeinen“ länger außer Landes zu bleiben befugt waren, wenn sie dies den Behörden annoncierten, empfänden die gehobenen Berufe als "behördliche Bevormundung“ und „Maßnahme einer Polizeiaufsicht", welche „eines freien Mannes unwürdig" sei. ${ }^{97}$

Ungeachtet Benešs Zusagen hatte nun allerdings auch die deutsche Gesandtschaft an der Durchführungspraxis vieles auszusetzen. ${ }^{98}$ Diese - so das mit dem Ersuchen um Nachverhandlungen gekoppelte Resümee Ende August - sei nach wie vor so rigoros, daß Betriebe aus Furcht vor Unannehmlichkeiten von der Einstellung Reichsdeutscher Abstand nähmen. ${ }^{99}$ Als drückend empfanden Firmen in Deutschland die hohen, oft willkürlich bemessenen Gebühren für Angestellte, die in Zweigniederlassungen in der ČSR entsandt wurden. Die knappe Befristung der Bewilligungen verursachte hohe Kosten, verbunden mit grundsätzlicher Ungewißheit über die Weiterbeschäftigungsmöglichkeiten. ${ }^{100}$ Die Presse in Deutschland wurde nicht müde, unter Ausmalung offensichtlich absurder bzw. schikanöser Einzelentscheidungen das Arbeitsmarktgesetz als Produkt "durchsichtiger tschechisch-chauvinistischer Tendenzen" anzuprangern und Beneš des Bruchs seiner Versprechungen vom Juli zu bezichtigen. Man könne sich, so etwa die Leipziger bzw. die Münchener Neuesten Nachrichten Ende Dezember, des Eindrucks nicht erwehren, „als wenn der Verhandlung dieser Angelegenheit bei den amtlichen deutschen Stellen nicht jene energische Aufmerksamkeit geschenkt wird, die im Interesse des deutschen Prestiges notwendig ist" ${ }^{101}$ Auch nicht untätig blieben die deutschen Abgeordneten im Prager Parlament, wo etwa der Deutschnationale Horpynka den deutschen Regierungsparteien vorwarf, Beneš nicht energisch genug bearbeitet $\mathrm{zu}$ haben. ${ }^{102}$

Das Bündel, in dem Handelsvertrag, Arbeitsmarktübereinkunft und die Markprioritätenfrage verschnürt waren, war nicht leicht zu entknoten. In der ersten Oktoberhälfte

97 BayHStA, MA 103 108, Hilfsverein deutscher Reichsangehöriger zu Aussig an den bayerischen Ministerpräsidenten, 18.12.1928. - Aktenvermerk Bayerische Staatskanzlei vom 2.1.1929. Reichsdeutsche Vereine in der ČSR an den Bayerischen Ministerpräsidenten Held, 17. 1.1929. Der Eingang der Denkschrift in München wurde am 19.4.1929 bestätigt. - Hilfsverein deutscher Reichsangehöriger zu Aussig an Bayerisches Staatsministerium des Äußern, 9.3.1929.

98 So gab es etwa den „Formularbescheid“, in dem vielen langjährigen reichsdeutschen Mitarbeitern mit der Kündigung gedroht wurde, falls sie nicht binnen einer bestimmten Frist den Befreiungsschein vorlegen konnten.

99 SÚA, MSP, Karton 2946, E 4221/1928-29, Gesandtschaft Prag an MZV, 23. 8.1928.

100 HStA Dresden, MWi, 325, 4130, Band 16, Handelskammer zu Dresden an Sächsisches Wirtschaftsministerium, 25. 10. 1928. - Handelskammer Zittau an Sächsisches Wirtschaftsministerium, 5. 12.1928.

101 LNN vom 23. 12. 1928. - Fast identischer Wortlaut in: MNN vom 28.12.1928.

102 BArch-B, RMWi 2896, Gesandtschaft Prag an AA, 23. 10.1928. 
1928 schlug Beneš der deutschen Seite vor, ihren Widerstand gegen die Handelsvertragsverhandlungen fallenzulassen und die Forderungen in der Markprioritätenfrage gegen anderweitige Zugeständnisse aufzugeben. Zur Verhandlungsmasse geschlagen wurde nun auch die Frage der bis 1918 mehrheitlich in deutschem Besitz befindlichen privaten Eisenbahnen in der Tschechoslowakei, etwa der Aussig-Teplitzer und der Buštehrader, deren Verstaatlichung eine - so die deutsche Polemik - „Tschechisierung“ des Personals nach sich gezogen hatte; als letzte „Bastion des Deutschtums“ war der Egerer Bahnhof übriggeblieben. ${ }^{103} \mathrm{Da}$ jedoch wegen der überaus starken emotionalen Befrachtung der Materie tschechische Konzessionen in diesem Punkt schwerlich zu erwarten waren, faßte die Prager Gesandtschaft das Arbeitsmarktgesetz und seine Anwendung auf Reichsdeutsche als erstrangiges Kompensationsobjekt ins Auge. Im Falle eines Nachgebens der Gegenseite in dieser Frage hielt Koch die Wiederaufnahme der Handelsgespräche und das Fallenlassen der Markprioritätenfrage für vertretbar. ${ }^{104}$

Auch nach mehreren deutsch-tschechischen Unterredungen auf diplomatischer Ebene war Anfang Dezember 1928 der Stillstand in den drei eng miteinander verwobenen Fragen nicht überwunden. ${ }^{105}$ Die tschechoslowakische Seite war weiterhin zögerlich; sie befürchtete von Arbeitsmarktkonzessionen eine Zurückdrängung des tschechischen Elements in der Wirtschaft der Republik, weil die Arbeitgeber in der ČSR vorzugsweise Reichsdeutsche auf die führenden Stellen hievten. „Heute noch“, so das Kölner Konsulat, "wo die Industrie bei uns zum großen Teil in deutscher Hand ist, wäre es für einen kleineren Staat mit einer solch starken, beinahe kompakten deutschen Minderheit im Grenzgebiet verfrüht, seine eigenen Vorkehrungen zu lockern und sich so der Gefahr der nationalen Expansion seines größeren, in dieser Hinsicht erfahrenen Nachbarn auszusetzen" ${ }^{106}$ Die Jahresvollversammlung des Hauptverbands am 9. März 1929 hingegen forderte mit Hinweis auf die nach wie vor günstige Arbeitsmarktlage erneut die Außerkraftsetzung ${ }^{107}$, und im April rechnete Otto Goltz als Vorsitzender des deutschen Arbeitgeberverbandes in der "Wirtschaft" grundsätzlich mit der Parole vom „Schutz der

103 Vgl. die Darstellung des Problems in: PA, R 73 825, Legationssekretär von Strahl, Die politische und wirtschaftliche Lage der deutschstämmigen Bevölkerung Böhmens und die Bestrebungen der tschechoslowakischen Regierung zur Stärkung und Festigung ihrer staatlichen Autorität in dem geschlossenen deutschen Sprachgebiete unter besonderer Berücksichtigung der Verhältnisse in Nordböhmen, 13.3.1925, S.60f. - Deutsche Paßstelle Eger an Gesandtschaft Prag, 30.5. 1925.

104 PA, II, Handel 13, Tschechoslowakei, Band 11, Gesandtschaft Prag an AA, 12. 10. 1928. AA/Ritter an RMWi, 30. 10. 1928. - RMWi an AA, 26.11.1928.

105 Zur Unterredung zwischen Koch und Krofta Ende Oktober vgl. PA, II, Handel 13, Tschechoslowakei, Band 11, Gesandtschaft Prag an AA, 1. 11. 1928. - Zum Stand Anfang November vgl. auch die Unterredung zwischen Köpke und Krofta: AA/Aufzeichnung Köpke vom 3.11.1928, S. 259f., in: ADAP, Serie B, Band X, S. 259-262. - Zum Stand Anfang Dezember vgl. PA, II, Handel 13, Tschechoslowakei, Band 11, Gesandtschaft Prag an AA vom 1.12.1928.

106 SÚA, MSP, Karton 2946, E 4221/1928-29, Tschechoslowakische Gesandtschaft Berlin an alle tschechoslowakischen Konsulate in Deutschland, 7.11.1928. - Tschechoslowakische Gesandtschafi Berlin an MZV, 21.12.1928, auf der Basis der Berichte des Dresdner Konsulats vom 20.11.1928, des Kölner Konsulats vom 26.11. und des Hamburger Generalkonsulats vom 10. 12. 1928, jeweils an MSP.

107 Vollversammlung des DHI am 9. 3. 1929, in: MDHI 10 (1929), S. 219. - Die im Februar 1929 auf 55224 gestiegene Arbeitslosenzahl erklärte der DHI mit saisonalen Faktoren: Vgl. MDHI 10 (1929), S. 325. 
nationalen Arbeit" ab: Den "geschlossenen Handelsstaat" und einen „Schutzzoll“ für Arbeitskräfte könne sich ein kleiner, weitestgehend in die Weltwirtschaft verflochtener Staat nicht leisten. ${ }^{108}$

Am 28. Januar hatte Beneš allerdings bereits die Wiederaufnahme des Fadens auf den im Vorjahr geschaffenen Grundlagen vorgeschlagen und erneut die kulante Behandlung individueller Eingaben ungeachtet des Buchstabens der Bestimmungen zugesichert; reichsdeutsche Angestellte unter Vorwänden loszuwerden sei nicht die Absicht. ${ }^{109}$ Die deutsche Seite löste das Junktim mit der Markprioritätenfrage, in der Prag sich nach wie vor intransigent zeigte. ${ }^{110}$ Die Arbeitsmarktgespräche vom 13. bis zum 17. Mai 1929 in Berlin führten zu einer Vereinbarung, die allerdings - ebenso wie 1923 - im Gesetzblatt nicht kundgemacht wurde: Eine - so der Hauptverband - „eigentümliche Geheimnistuerei“. ${ }^{111}$ Die Übereinkunft galt bis zum Ende des Jahres und verlängerte sich, falls sie nicht gekündigt wurde, automatisch um jeweils ein Jahr. Angehörige des einen vertragsschließenden Staates unterlagen im anderen keinen Beschränkungen, wenn sie sich seit dem 30. April 1923 dort ununterbrochen aufgehalten hatten. Sie erhielten in diesem Fall den Befreiungsschein. Erlaubnisse für bewilligungspflichtige Beschäftigungen wurden in Härtefällen, d. h. nach mindestens siebenjährigem Aufenthalt im Lande, grundsätzlich erteilt. Der Aufenthalt galt nicht als unterbrochen bei Abwesenheit von bis zu sechs Wochen jährlich oder sobald der Nachweis der Unumgänglichkeit erbracht war. Ablehnungen konnten der vorgesetzten Behörde vorgelegt werden; hatte bereits eine Bewilligung bestanden, so zeitigte der Rekurs aufschiebende Wirkung. Als jährliche Gebührenhöchstgrenze waren in Deutschland 15 RM festgesetzt. Die C SR behielt die Staffelung nach Jahreseinkommen bei, senkte aber die Sätze. ${ }^{112}$ Prag konzedierte eine wohlwollende Behandlung von Anträgen auf Arbeitserlaubnis unter Berücksichtigung der Arbeitsmarktlage. Die besonders der tschechischen Seite am Herzen liegenden Bewilligungen für Grenzgänger sollten entgegenkommend gehandhabt und an eine vergleichsweise geringe Gebühr gebunden werden. ${ }^{113}$ Wurde in den Verhandlungen, die dem Bericht des bayerischen Gesandten zufolge "sehr langwierig, zum Teil auch recht hitzig“ verliefen, das deutsche Maximalziel einer gänzlichen Freistellung der Reichsdeutschen vom Arbeitsmarktgesetz auch verfehlt, so hatte die tschechische Seite doch Konzessio-

108 Goltz, Schutz.

109 SÚA, MSP, Karton 2946, E 4221/1928-9, Verbalnote des MZV an Gesandtschaft Prag, 28.1. 1929.

110 PA, II, Handel 13, Tschechoslowakei, Band 12, Gesandtschaft Prag an AA, 1. 2. 1929. - Aktenvermerk AA/Abteilung $\mathrm{V}$, an Windel und Ritter, 4.2.1929. - AA an RMFin, RMWi, RMA, 5. 2. 1929. - Sitzung des Handelspolitischen Ausschusses am 8. 2.1929.

111 MDHI 10 (1929), S. $624 \mathrm{f}$.

112 Bei Jahreseinkommen bis zu 18000 Kronen betrug die Gebühr 100 Kronen, bei bis zu 42000 Kronen: 160 , bei bis zu 60000 Kronen: 400 . Darüber hinausgehende Einkommen konnten mit bis zu 1000 Kronen belastet werden.

113 SÚA, MSP, Karton 2946, E 4221/1928-9, Niederschrift vom 17. 5. 1929 über die Verhandlungen zwischen der deutschen und der tschechoslowakischen Regierung über Fragen des Arbeitsmarktes vom 13. bis 17. 5. 1929. - BayHStA, MA 103 108, Der Reichsarbeitsminister an die Regierungen der Länder u. a., 18.5.1929, mit der Vereinbarung vom 17.5.1929 in der Anlage. SÚA, MSP, Karton 2946, E 4221/1928-9, MSP an Handels- und Gewerbekammer Troppau, 4. 10. 1929 (Konzept). 
nen beim „ununterbrochenen Aufenthalt“", in der Gebührenfrage sowie bei den „Härtefällen" gemacht und eine Überprüfung bereits ausgesprochener Ablehnungen im Lichte der Vereinbarungen zugestanden. ${ }^{114}$

Ursache des Tauziehens um die Inkraftsetzung der Vereinbarung war das fortbestehende Junktim mit den Handelsvertragsverhandlungen. $\mathrm{Da}$ sich das deutsche Reich nach den vorangegangenen Zusagen dem Drängen Prags auf Wiederaufnahme dieser Gespräche kaum mehr entziehen konnte, ohne die Arbeitsmarktvereinbarung zu gefährden, bestand das Auswärtige Amt auf deren vorgängiger Inkraftsetzung. Ein Indiz für die erheblichen internen Widerstände gegen ein solches Vorgehen war die Bitte Friedmanns, des Leiters der handelspolitischen Abteilung im Prager Außenministerium, nicht zu „urgieren“, da wegen der Abkoppelung der Arbeitsmarkt- von den Handelsfragen die Position seines Hauses schwierig genug sei. ${ }^{115}$ Im Halbdunkel der Prager Kulissen spielten sich nun dramatische Szenen ab: Im ersten Julidrittel ließ sich Fürsorgeminister Šrámek, Vertreter des Ministerpräsidenten, zu einer Zustimmung herbei, so daß das Außenministerium bereits eine Delegation in Berlin ankündigen zu können meinte. Nun aber erhoben sich neuerliche Widerstände im Handels- und im Landwirtschaftsministerium, wo man die Trümpfe nicht leichtfertig aus der Hand geben mochte. Kaum hatte das Außenministerium die Einwilligung der beiden Ressorts erwirkt, begann Šrámek zu schwanken und mußte aufs neue bearbeitet werden. ${ }^{116}$ Die Zustimmung wurde erteilt ${ }^{117}$; der Minister entwich unmittelbar im Anschluß daran jedoch, ohne nähere Weisungen zu hinterlassen, aufs Land und löste eine hektische Suchaktion aus. Erst nach deren Abschluß wurde am 11. Juli mitgeteilt, alle Hindernisse seien nunmehr endgültig beseitigt. ${ }^{118}$

114 BayHStA, MA 103 108, Staatliche Bayerische Wirtschaftsstelle in Berlin an das Bayerische Staatsministerium des Äußeren vom 17.5.1929.

115 PA, II, Handel 13, Tschechoslowakei, Band 12, AA/Aufzeichnungen Windel vom 14. 5. und vom 7.6.1929. - Aufzeichnung Fischer vom 10.6.1929 über sein Gespräch mit Friedmann am 8. 6. 1929. - AA an RMFin, RMWI, RMEL, 12.6.1929.

$116 \mathrm{Zu}$ dem deutschen Gesandtschaftsvertreter Holzhausen äußerte Krofta: „Sramek (!) hat mir die Inkraftsetzung gestern abend gelegentlich eines Diners versprochen. Aber Sie wissen ja selbst, was das Wort eines Ministers wert ist: Er sagt erst zu, dann kommt der Referent und äußert seine Bedenken, und dann fällt er wieder um": Vgl. PA, II, Handel 13, Tschechoslowakei, Band 12, Gesandtschaft Prag an AA, 12.7.1929.

117 ... wobei sachfremde Motive nicht auszuschließen sind: Dem Bericht der Prager Gesandtschaft zufolge war der Minister zugänglich „nicht zuletzt auch deshalb, weil er Beneš, der die fremden Bischöfe bei der Orelfestlichkeit so freundlich aufgenommen habe, neuerdings freundlicher gesonnen sei“: Vgl. PA, II, Handel 13, Tschechoslowakei Band 12, Gesandtschaft Prag an AA vom 12.7. 1929, Anlage: Aufzeichnung Holzhausen über das Gespräch mit Krofta am 11.7.1929.

118 BArch-K, R 43 I/11 23, Telegramm der Gesandtschaft Prag vom 3. 7. 1929. - PA, II, Handel 13, Tschechoslowakei, Band 12, Gesandtschaft Prag an AA, 12.7.1929. 